\title{
Understanding The Current Facts And Principles Of Mental Health Systems Planning
}

\author{
William A. Anthony, Mikal Cohen, and William Kennard \\ Center for Psychiatric Rehabilitation, Boston MA
}

\begin{abstract}
The state mental health services planning encouraged by Pub.L. 99-660, TitleV, will be a very different process from the services planning of previous decades. The services planning stimulated by this new legislation will be influenced by a philosophy and set of values that contrast markedly with past services planning. In this article, service planning principles are articulated that can guide the planning of a comprehensive community-based service system. Yet, no matter how well crafted the plan; its worth is based on what it does for the people being served. New technology exits to change the program structures and staff competencies in ways that will lead to better client outcomes. The challenge of successfully implementing these new service plans will only be met when mental health authorities directly support the use of the new technologies.
\end{abstract}

It appears that mental health system planning in the 1990s will be influenced by a vision and a philosophy that is very different from previous mental health planning efforts. Stimulated by a developing consensus about the underlying philosophy of community support and rehabilitation (Anthony, 1992; Parrish, 1989; Turner \& TenHoor, 1978), mental health planning is riding a wave of optimism about what could be, realistically tempered by a trough of pessimism about what currently exits and how much needs to be done.

The articles in this section describe this future vision and present reality (Chamberlin \& Rogers, 1990; Kennedy, 1990; Romeo, Mauch, \& Morrison, 1990; Weisburd, 1990). The Model Plan for a Comprehensive, Community-Based System (National Institute of Mental Health (NIMH), 1987), a technical assistance document to help state implement Pub.L. 99-660 (State Comprehensive Mental Health Plan Act, 1986), is imbued with the community support and rehabilitation philosophy that undergrads this new vision. This philosophy specifically includes (a) understand the person with mental illness as a person first, with basic needs and goals similar to other members of the community; (b) involving consumers and family members in system planning and implementation activities; (c) recognizing the family as a resource to the helping effort; and (d) developing services that are consumer-centered and empowering.

This philosophy is the foundation for service system planning. It must also be reflected in the overall mission of the state plan. The NIMH (1987) has provided the following example of a mission statement as one that is consistent with this new philosophical base:

To implement programs and services that assist adults with severe, disabling mental illness to control the symptoms of the illness; to develop the skills and acquire the supports and resources they need to succeed where they choose to live, learn, and work; and to maintain responsibility, to the greatest extent possible, for setting their own goals, directing their own lives, and acting responsibly as members of the community. (p. 12) 
To develop new plans that incorporate this philosophy, planners must not only think differently about the possibilities for consumers in their future service system, they must also think smarter. They must do away with their outdated assumptions and be guided by current knowledge and principles.

\section{Old Planning Myths and New Planning Principles}

Planners of a comprehensive community-based system must be armed with new knowledge; they must be disarmed of old planning assumptions. A description of 10 facts and principles about which planners must be knowledgeable in order to plan follows.

1. Consumers of mental health services can identify realistic goals for themselves that can then be factored into planning a system's services. Previous system wide planning efforts seemed to mistakenly assume that persons with severe psychiatric disabilities will not be able to come up with goals or that the goals they come up with will be destructive (e.g., will harm someone) or unrealistic (e.g., wants to be an astronaut). The fact is that, if given the opportunity and support, most clients can identify realistic goals that planners can use as the basis for their service system design. When consumers are asked about their goals in a supportive manner, the goals they mention are the same goals that other persons would mention-satisfying jobs, decent places to live, a chance to return to school, and a reduction of psychological distress. System planners must ensure that their planning proceeds from a good understanding of the goals of the persons whom the system is designed to serve.

2. The mission of the state department of mental health is to help people function better so that they can become more successful and satisfied in their various living, learning, working, and/or social environments, with the least amount of ongoing assistance from agents of the mental health system. This mission is a variation of the mission suggested in the model plan (NIMH, 1987). The key difference between this suggested mission and prior descriptions of the mission of state mental health departments is that the focus of the preferred mission is on outcomes for the clients rather than on process objectives for the mental health authorities. Historically, the state level mission has been to provide "comprehensive services" or "continuity of care" are quality control objectives that may or may not achieve client outcomes. When clients are asked what their ultimate mission or goals are, none of them indicate "comprehensive services" -neither should mental health service systems.

3. The role of the state hospital in the system plan should be consistent with the state department's overall mission. Historically, system-level mission statements have incorrectly written that the elimination of state hospital beds was a major element of the mission of the state department of mental health. However, the ultimate focus of the plan should be on the hospital's role, not the size. The hospital is apart of the community, and a community-based system of services, the hospital is designed, like other services, to help people live successfully in the community, not simply to keep them out the community or keep them in. The emphasis in the plan is on creating services consistent with the mission of the system, and not simply on eliminating beds. Bed reduction is a byproduct of a successfully achieved mission, not a mission in and of itself.

4. Improving client functioning, and not simply maintaining people in the community, must be a part of the system's mission. A maintenance-only mission is yesterday's mission. A variety of programs have demonstrated their capacity to maintain people in the community (e.g. Cannady, 1982; Stein \& Test, 1980). Although such programs have not yet been routinely 
implemented nationwide, a system mission of community maintenance reflects yesterday's accomplishments and values. Consumers "maintained" in the community are now asking, where can I go in it? What can I do in it? Helping persons with psychiatric disability to grow in the community, rather than just to survive in the community, must be the focus of the system's mission.

5. $\quad$ Psychiatrically disabled persons' skills and supports relate to community outcomes more strongly than do their symptoms. System planners must ensure that their services provide for skill development and support development, and not just symptom relief. Both new and old service dollars need to be directed at programs that focus on skill and support development outcomes. System planners must realize that persons with psychiatric disabilities are limited not only by their major psychiatric symptoms but primarily by their persistent social vocational deficits and exaggerated emotional response to stressful life events. The substance of a system's service delivery programs must reflect this fact.

6. Persons who are psychiatrically disabled need different services, at different times, and at different levels of intensity. Persons with psychiatric disabilities do not need the same kinds of services. Thus, the service system must develop a large range of service alternatives, packaged differently for different clients. These unique services for each client are tied together by a common mission. The individual service package flows from the person's goals and an assessment of the skills and supports needed to achieve these goals.

For example, the type of housing in which one resides need not dictate the kind and intensity of services one receives, or vice versa. The fact is that persons should receive the kinds of services they need and want, no matter what their housing situation. System planners must tie their services to the person and not to the house. A client shouldn't have to live in a group home in order to receive the kind of services he or she needs, or attend day treatment to live in the type of home he or she wants. A wide range of services must be provided over the wide range of housing options, which increasing and decreasing levels of intensity and support as needed by the client. One shouldn't have to continually change residences in order to get more, less, or different services.

7. Many persons with psychiatric disabilities don't want the services the system provides because they often find these services unappealing, inappropriate, or demeaning. The high attrition rates of mental health programs are not a function of client deficits, but rather service deficits. Thus, system planners must constantly check to see if the services created are consistent with the philosophy and values of a community-based services system (NIMH, 1987). Explicit statements of values in the plan provide one yardstick against which implementation can be judged. The values specified in the plan can do more than help make the planners feel good; they help the implementers of the plan do good.

Some persons with psychiatric disabilities who want and need services won't seek them out. Systems of the future will be judged not just by how well clients are doing who seek out services, but by how well persons with psychiatric disabilities are doing who do not seek out services. Service systems planning must include ways to reach and help these latter folks in their plans.

8. $\quad$ Personnel who work in programs serving persons with severe mental illness have not been appropriately trained, nor are they "naturals." Most staff are untrained in the new technology of service delivery. In addition, many dedicated and skilled staff who elect to work 
in the mental health system become frustrated because the program and system is often structured so that it interferes with their ability to act on their good intentions. System planners must recognize that skilled and dedicated personnel are their most important and costly resource. The plan must indicate who will be trained, in what, and by whom. What will be the role of state colleges and universities in the training effort? Persons who are successfully recovering from severe mental illness, when asked what has been most helpful to their recovery, almost invariably mention a skilled and dedicated person. Skilled, dedicated people are the bottom line-and that fact must be reflected in the plan.

9. New technology and new facts relevant to community support and rehabilitation are being reported almost daily, and these new developments must be incorporated into the plan in an ongoing manner. The field is changing rapidly and planners must remain current with these changes. Thus, there must be a plan to ensure an ongoing planning capacity. Service programs such as supported housing, supported learning, and supported work have been very recent developments. Training programs in functional assessment and family psycho-education are examples of new skills that practitioners can now learn. Consumer preference, rather than client levels of function and symptomatology, is only just now being considered as a basis for system planning. Unlike the "planning" that preceded the deinstitutionalization initiative, a major change in services cannot be planned, implemented, and then not revisited for 20 years!

10. Enough knowledge now exists to successfully plan for improved community-based services for persons with severe mental illness. There are those who want to wait for the results of more longitudinal studies of various service alternatives before improving the system. The fact is that too much new knowledge and technology exists not to plan for a better system of services. Thus, there is an opportunity for improved service systems, based on existing knowledge. State system planners who do not yet see this opportunity can be educated about this new knowledge and technology. Consumers and their families have been waiting long enough. Old myths must be discarded. We must begin to use what we already know.

\section{Challenges to Implementing the Plan}

No matter how well crafted the plan, no matter how steeped the plan in the appropriate philosophy, no matter how current the planner's knowledge, no matter how strategic the planning process - the proof of the plan is what is does for the person being served. A plan can do nothing unless the implementors of the plan (i.e., practitioners and administrators) are expert in the technology needed for successful implementation.

Until now, most of the state services planning have focused on the process of planning rather than the sub-stance of the plan. A strategic planning process has been adopted by many states (Goodrick, 1988). Through strategic planning, states have arrived at various service configurations to serve as blue prints for the design of a better services delivery system (Cohen \& Anthony, 1988). The quintessential next step is to change the substance of the services (Cohen, 1989). There have been technological advances in the filed that provide applied knowledge about how to develop the program structures and staff competencies required for improved services to clients (Anthony, Cohen, \& Farkas, 1987).

New knowledge merged with a new philosophy has produced a new technology. The ultimate goal of the planning process will be to get this technology routinely used. 


\section{What Is This New Technology?}

How to help persons with severe mental illness is no longer a mystery. Technology that contains applied knowledge that can be easily used in a replicable fashion is being developed. Technologies exist or are emerging to change program structures and staff competencies in ways that will lead to decreases in clients' symptoms and improvements in clients' skills, supports, and role performance.

Although the technologies vary considerably with respect to their level of detail, in many content areas the technology has developed to the point at which instructors can teach it, service providers can perform it, administrators can monitor it, researchers can evaluate it, consultants can shape it, and consumers and family members can observe it before they participate in it. Service models, training curricula, and consultation strategies exist. Table 1 lists those technologies that have progressed to the stage that either printed material or consultants are available to assist in the adoption of the technology. References refer the reader to the technology itself or to where the reader can learn more about the technology.

\section{Table 1}

Technologies To Improve Services for People With Psychiatric Disabilities

Technology

Developing a psychosocial rehabilitation center

Teaching clients medication management skills

Conducting family psycho-educational groups

Developing consumer-operated self-help

programs

Developing psychiatric rehabilitation programs

Teaching social skills to clients

Developing a rehabilitation program in a

postsecondary sitting

Developing supported employment programs

Developing a program of assertive community treatment

Teaching in-service and pre-service personnel how to set overall rehabilitation goals, conduct functional assessments, and teach skills

Teaching in-service and pre-service personnel how to do case management
Source examples

Beard, Propst, \& Malamud (1982)

Wallace, Boone, Donahoe, \& Fy (1985)

Anderson, Hogarty, \& Reiss (1980)

Zinman, Harp, \& Budd (1987)

Farkas \& Anthony (1989); Farkas, Cohen, \& Nemec (1988)

Leberman et al. (1986)

Unger, Danley, Kohn, \& Hutchinson (1987)

Danley \& Mellen (1987)

Hoult (1986); Stein \& Test (1980); Witheridge, Dincin, \& Appleby (1982)

Cohen, Danley, \& Nemec (1985); Cohen, Farkas, \& Cohen (1986); Cohen, Farkas, Cohen, \& Unger (in press)

Cohen, Nemec, Farkas, \& Forbess (1990); Modrcin, Rapp, \& Chamberlain (1985)

The adoption and use of technology is to a certain extent dependent on the way the technology is described and packaged (Muthard, 1980). A well-defined technology, rather than an ideology or belief system, is necessary to overcome natural resistances to change (Cohen, 1989, Gross, Giacquinta, \& Bernstein, 1971). Some of the newer technology useful in improving service to the severely mentally ill is defined in detail and packaged to ensure easy use. Use of some of the new technology depends on the participation of the developers. Also important to technology transfer are the characteristics of the users of the technology (Gomery, 
1983). The more knowledgeable and skilled the technology user, the less well developed the technology needs to be, because the user is capable of adding the necessary details.

Attempts to implement the new state mental health plans that are based on a new responsive philosophy will lead to either the adoption of new technology or to discarding the new philosophy. If new technologies are adopted, there will be a change not only in the way services are planned but in the way services are delivered. 


\section{References}

Anderson, C., Hogarty, G., \& Reiss, P. (1980). Family treatment of adult schizophrenic patients: A psychoeducational approach. Schizophrenia Bulletin, (6), 490-505.

Anthony, W. A. (1982). Explaining "psychiatric rehabilitation" by an analogy to "physical rehabilitation". Psychosocial Rehabilitation Journal, 5(1), 61-65.

Anthony, W. A., Cohen, M. R., \& Farkas, M. D. (1987). Training and technical assistance in psychiatric rehabilitation. In A. T. Meyerson \& T. Fine (Eds.), Psychiatric disability: Clinical, legal, and administrative dimensions (pp. 251-269). Washington, D. C.: American Psychiatric Press.

Beard, J. H., Propst, R. N., \& Malamud, T. J. (1982). The Fountain House model of psychiatric rehabilitation. Psychosocial Rehabilitation Journal, 5(1), 47-53.

Cannady, D. (1982). Chronics and cleaning ladies. Psychosocial Rehabilitation Journal, 5(1), 13-16.

Chamberlin, J., \& Rogers, J. A. (1990). Planning a community-based mental health system: Perspective of service recipients. American Psychologist, 45(11), 1241-1244.

Cohen, M. (1989). Integrating psychiatric rehabilitation into mental health systems. In M. Farkas \& W. A. Anthony (Eds.), Psychiatric rehabilitation programs: Putting theory into practice. The Johns Hopkins series in contemporary medicine and public health (pp. 162191). Baltimore, MD: The Johns Hopkins University Press.

Cohen, M., \& Anthony, W. A. (1988). A commentary on planning a service system for persons who are severely mentally ill: Avoiding the pitfalls of the past. Psychosocial Rehabilitation Journal, 12(1), 69-72.

Cohen, M., Danley, K. S., \& Nemec, P. B. (1985). Psychiatric rehabilitation training technology: Direct skills teaching (Trainer package).Boston: Boston University, Center for Psychiatric Rehabilitation.

Cohen, M., Nemec, P., Parkas, M., \& Forbess, R. (1990). Psychiatric rehabilitation training technology: case management Boston: Boston University, Center for Psychiatric Rehabilitation.

Cohen, M. R., Farkas, M. D., \& Cohen, B. F. (1986). Psychiatric rehabilitation training technology: Functional assessment (Trainer package). Boston: Boston University, Center for Psychiatric Rehabilitation.

Cohen, M. R., Farkas, M. D., Cohen, B. F., \& Unger, K. V. (1990). Psychiatric rehabilitation training technology: Setting an overall rehabilitation goal (Trainer package). Boston: Boston University, Center for Psychiatric Rehabilitation. 
Danley, K. S., \& Mellen, V. (1987). Supported employment for persons with severe mental illness. Psychosocial Rehabilitation Journal, Special Issue (11), 2.

Farkas, M. D., \& Anthony, W. A. (Eds.). (1989). Psychiatric rehabilitation programs: Putting theory into practice. Baltimore, MD, USA: Johns Hopkins University Press.

Farkas, M. D., Cohen, M. R., \& Nemec, P. B. (1988). Psychiatric rehabilitation programs: Putting concepts into practice? Community Mental Health Journal, 24(1), 7-21.

Gomory, R. E. (1983). Technology development. Science, 230, 576-580.

Goodrick, P. (1988). Strategies for state and local mental health system planning. Washington, D. C.: COSMOS Corporation.

Gross, N. J., Giacquinta, B., \& Bernstein, M. (1971). Implementing organizational innovation.Basic Books: New York.

Hoult, J. (1986). Community care of the acutely mentally ill. British Journal of Psychiatry, 149, 137-144.

Kennedy, E. M. (1989). Community based care for the mentally ill: Simple justice. American Psychologist (45), 1238-1240.

Liberman, R. P., Mueser, K. T., Wallace, C. J., Jacobs, H. E., Eckman, T., \& Massel, H. K. (1986). Training skills in the psychiatrically disabled: Learning coping and competence. Schizophrenia Bulletin, 12(4), 631-647.

Modrcin, M., Rapp, C. A., \& Chamberlain, J. (1985). Case management and psychiatrically disabled individuals: Curriculum and training program.Lawrence, K.S.: University of Kansas, School of Social Welfare.

Muthard, J. E. (1980). Putting rehabilitation knowledge to use. (Rehabilitation Mongraph Number 11.).Gainesville, FL: Rehabilitation Research Institute.

National Institute of Mental Health. (1987). Toward a model plan for a comprehensive, community-based mental health system. Rockville, MD: Division of Education and Service Systems Liasion.

Parrish, J. (1989). The long journey home: Accomplishing the mission of the Community Support Movement. Psychosocial Rehabilitation Journal, 12(3), 107-124.

Romeo, T., Mauch, D., \& Morrison, E. (1990). The art of strategic mental health planning in Rhode Island. American Psychologist (45), 1253-1256.

State Comprehensive Mental Health Plan Act of 1986, Public Law 99-660, Title V. (1986). 
Stein, L. I., \& Test, M. A. (1980). Alternative to mental hospital treatment: I. Conceptual model, treatment program, and clinical evaluation. Archives of General Psychiatry, 37(4), 392397.

Turner, J. C., \& TenHoor, W. J. (1978). The NIMH Community Support Program: Pilot approach to a needed social reform. Schizophrenia Bulletin, 4(3), 319-349.

Unger, K. V., Danley, K. S., Kohn, L., \& Hutchinson, D. (1987). Rehabilitation through education: A university-based continuing education program for young adults with psychiatric disabilities on a university campus. Psychosocial Rehabilitation Journal, 10(3), 35-49.

Wallace, C. J., Boone, S. E., Donahoe, C. P., \& Foy, D. W. (1985). Psychosocial rehabilitation for the chronic mentally disabled: Social and independent living skills training. In D. Barlow (Ed.), Behavioral treatment of adult disorders (pp. 461-501). New York: Guildford Press.

Weisburd, D. E. (1990). Planning a community-based mental health system: Perspective of a family member. American Psychologist(45), 1245-1248.

Withridge, T. F., Dincin, J., \& Appleby, L. (1982). Working with the most frequent recidivists: A total team approach to assertive resource management. Psychosoical Rehabilitation Journal(5), 9-11.

Zinman, S., Harp, H., \& Budd, S. (1987). Reaching across: Mental health clients helping each other. Sacramento: California Network of Mental Health Clients. 